\title{
Designing a Women's Refuge: An Interdisciplinary Health, Architecture and Landscape Collaboration
}

\author{
Suzanne Dean ${ }^{1}$, Claire Williams ${ }^{1}$, Samantha Donnelly ${ }^{2} \&$ Tracy Levett-Jones ${ }^{1}$ \\ ${ }^{1}$ Faculty of Health, University of Technology Sydney, Australia \\ ${ }^{2}$ Faculty of Design, Architecture and Building, University of Technology Sydney, Australia \\ Correspondence: Suzanne Dean, Faculty of Health, University of Technology Sydney, Australia
}

Received: November 1, 2017

Accepted: December 8, 2017

Online Published: December 11, 2017

doi:10.5430/ijhe.v6n6p139

URL: https://doi.org/10.5430/ijhe.v6n6p139

\begin{abstract}
University programs are currently faced with a number of challenges: how to engage students as active learners, how to ensure graduates are 'work ready' with broad and relevant professional skills, and how to support students to see their potential as agents of social change and contributors to social good. This paper presents the findings from a study that explored the impact of an authentic, interdisciplinary project with health, architecture and landscape students. This project facilitated students' entrée into the lived experience of women and children requiring refuge services as a result of homelessness and/or domestic violence. Students collaborated with stakeholders from the refuge sector, visiting sites, undertaking individual research, exchanging ideas and problem-solving, to develop a design guide for a women's refuge. Focus groups were conducted at the conclusion of the activity to gauge students' perceptions of the value of the activity. Results indicated that the 'hands-on' and collaborative nature of the learning experience in a real-world context was valued, primarily due to its direct relevance to professional practice. Architecture and landscape participants reported an increase in their understanding and knowledge of refuge clients, and many expressed a commitment to further learning and contribution to the sector. Nursing students felt that the authentic learning experience helped prepare them for the 'real world' of practice and that it aided development of their professional identities and capacity to effect real-world change. The learning activity had a positive impact on knowledge acquisition and students' confidence to act as agents of social change.
\end{abstract}

Keywords: Interdisciplinary learning, Authentic assessment, Students as agents of social change, Collaboration

\section{Introduction}

University programs are currently faced with a number of challenges: how to engage students as active learners, how to ensure that graduates are 'work-ready' with relevant communication and problem-solving skills rather than narrow discipline-based knowledge, and how to equip students with the skills to be creative, self-directed, life-long learners and contributors to social good. Authentic, interdisciplinary learning is increasingly seen as a way to address these challenges.

Interdisciplinary education differs from transdisciplinary and multidisciplinary education in that it aims to integrate knowledge from different disciplines. Whilst the literature includes discussion of numerous pedagogical approaches to meet this aim, the potential to make a real difference in real-world practice beyond the boundaries of a single discipline is a shared motivation for the use of this learning approach (Bateman \& Craig, 2015; Mansilla \& Duraising, 2007; Spelt, Luning, van Boekel, \& Mulder, 2015).

The objective of this study was to explore nursing, architecture and landscape students' perspectives of an interdisciplinary learning activity where they collaborated to develop a design for a women's refuge. The findings indicated that students' engagement in this 'hands-on' project had a positive impact on both their learning and their disposition to act as agents of social change.

\section{Literature Review}

Family violence and homelessness are pressing social issues in Australia and worldwide (Goldsmith, 2016; Moore, 2016). Approximately 520,000 Australians accessed homelessness services between 2011 and 2014 and 187,000 of these people sought assistance due to domestic violence. Domestic violence is understood to be one of the major causes of housing instability which includes homelessness (Baker, Cook, \& Norris, 2003). Women, in particular poor 
women, require a variety of services following separation from their abuser, and the first of these - immediate crisis intervention - includes housing provision. Women's refuges provide safe crisis accommodation in addition to emotional support and advocacy. Increasingly however, the demand for these shelters exceeds availability. Australian data from 2005-2006 highlight that nearly fifty percent of women who approached refuge services were turned away due to the lack of capacity within the sector (AIHW, 2007). Housing services are also challenged by the increasing number of older women accessing services, along with particularly vulnerable groups such as migrant and refugee women, and lesbian, gay, bisexual, transgender and intersex individuals (AIHW, 2016; Goldsmith, 2016). A lack of crisis accommodation often leads to women staying in abusive relationships (Goldsmith, 2016).

Domestic violence is widespread and it has devastating health, social and economic consequences, not only to the victim, but also to children and the community generally. The task of providing solutions to such a complex problem requires input from a range of disciplines: law, finance, social policy, housing, psychology and so on. Crisis accommodation in the form of refuge services provides a front line service and when considering the design of refuges, input from the health discipline is especially relevant because family violence and homelessness are a major cause of physical and mental harm. The contribution from architecture is also important because of the need for good design of both permanent and temporary accommodation.

Universities aiming to prepare students for life and work by equipping them with the knowledge and skills to make a difference recognize that learning is socially situated. Therefore, a useful teaching and learning strategy is to select contemporary social issues as the focus for learning. Two of the authors of this paper, have worked in practice with Women's refuge services and identified that this is an area which has potential for better design and better management in terms of health, architecture and landscape practices. Additionally there is a current focus on domestic violence and possible innovations to services provided for the victims of domestic violence and their children, in the media. The currency and social impact of this topic supports students to engage with curricula content they understand to be important. The authors of the current study identified the needs of women and children requiring the services of a refuge as an area that leant itself to a meaningful and authentic learning experience for nursing, architecture and landscape students.

Authentic learning is a pedagogical approach which enables students to develop 'robust knowledge' which is transferrable to professional practice (Herrington, Reeves, \& Oliver, 2014). Authentic learning has a number of key components: learning tasks mimic complex real-life situations; students are required to problem-solve by working both independently and in diverse teams, opening themselves to different ideas and perspectives; new understandings emerge from contact with the 'real world' of practice, and students build confidence as well as new knowledge through active participation (Knotts, Henderson, Davidson, \& Swain, 2009; Lombardi, 2007; Maina, 2004; Rule, 2006). Authentic learning is a good fit for interdisciplinary learning as the assumption embedded in both is that learning must go beyond pure disciplinary knowledge in order to prepare students for the real-world they will encounter upon graduation. There is a growing body of literature attesting to the benefits of authentic learning pedagogies as facilitators of transformative learning that helps to develop students' professional identity and capacity to effect real-world change (Bateman \& Craig, 2015; Bryson, 2016; Kreber, 2016; Zou, 2016).

Interdisciplinarity, multidisciplinarity and transdisciplinarity refer to ways in which the traditional boundaries between disciplines are broken down in the pursuit of more meaningful and engaging research and learning that addresses 'real-world' problems. In the modern era, knowledge is created and disseminated in multiple ways throughout society, and examples include citizen science (Bonney et al., 2014) and crowdsourcing (Aitamurto, 2015). There is an increasing impetus within universities to share knowledge and research activities across discipline boundaries, and with practitioners outside the university sector, as a way to be more relevant, connected and impactful, and to offer students richer and more meaningful learning experiences.

Multidisciplinary learning in higher education refers to its additive nature - it is one discipline being added to another (Spelt, Luning, van Boekel, \& Mulder, 2009). The differences between interdisciplinary learning and transdisciplinary learning are matters of debate within the literature. Park and Son (2010) assert that in interdisciplinary learning, students collaborate through interaction and learn to be 'knowledge collaborators' while transdisciplinary learning takes this a step further, and students learn to be 'knowledge producers'. Gibbs (2017) suggests that transdisciplinary learning 'transcends and integrates discipline paradigms' while Pohl (2011) is of the view that it entails 'a deep search for a unity of knowledge'. Such ambition was not within the scope of this project.

Interdisciplinary learning is arguably a necessary component of authentic learning because it reflects the reality of contemporary, team-based practice in modern workplaces. By facilitating open-mindedness, sound communication and respect for diversity, interdisciplinary learning can help prepare students for their future careers. As (Iwasiw, 
Goldenberg, \& Andrusyszyn, 2014) observed, if students learn in isolation from one another, it will be more difficult for them to communicate and collaborate with colleagues when they are practicing professionals. This can undermine workplace harmony and efficiency and even, in the healthcare setting, patient safety (Gilligan, Outram, \& Levett-Jones, 2014). Further, when work teams transcend organisational and disciplinary boundaries this leads to improved outcomes and reduced design and development costs (Sonnenwald, 1996).

This project sought to move outside discipline boundaries by bringing together students with different perspectives and approaches, to engage in open communication, knowledge-sharing and problem-solving. Further, because it was an 'authentic' learning activity, students interacted directly with stakeholders outside of the university setting who were affected by the issues being addressed (in this case, homelessness and family violence) (Gibbs, 2017).

Collaborative learning has been found to enhance student learning in a number of ways: it facilitates active engagement; it offers students opportunities to develop interpersonal and teamwork skills by working in task-oriented groups; it encourages students to value different perspectives; and it helps them to become life-long learners (Barkley, Cross, \& Major, 2005). Interdisciplinary collaboration also appeals because it facilitates the development of new insights and perspectives based on shared knowledge that can be immediately applied to real-life problems (Wall \& Shankar, 2008).Traditional discipline-specific education is said to focus on knowledge and skills specific to that one discipline which, in today's complex and dynamic social and work environments, is no longer relevant (Spelt et al., 2009). By integrating knowledge across disciplines, students should be able to explain a phenomenon, solve a problem, or create a product in ways that are impossible through a single discipline lens (Boix Mansilla \& Gardner, 2000).

The Refuge Project aimed to explore the impact of an authentic learning activity incorporating interdisciplinary collaboration in a health, social and design space. It also sought to determine whether students would emerge with the requisite skills and disposition to act in the future as agents of social change to address the pressing issues of homelessness and family violence.

\section{Learning Activity}

The twelve-week interdisciplinary learning activity was designed by academic staff from Faculty of Health and School of Architecture. The connections between these disciplines, while sometimes evident in practice, are less obvious in academic contexts where design schools focus on spatial and environmental issues and nursing schools focus on patient care. Contemporary nursing and architecture/landscape education, however, have clear commonalities of interest in regard to a focus on social good. The Faculty of Design, Architecture and Building at one leading Australian university, for example, advises prospective students that:

Creating sustainable, desirable and livable global cities is one of the great challenges facing the world today. Architecture and design professionals have the potential to shape our cities and transform urban life for the world's growing population... (UTS, 2017)

Addressing a significant contemporary social issue - the needs of women and children requiring refuge as a result of homelessness or family violence - the project required students from three different disciplines - nursing, architecture and landscape architecture - to work together in the development of a design for a refuge, incorporating both building and grounds.

Potential participants from nursing, architecture and landscape architecture were recruited based on the following criteria: complementarity of subject learning outcomes, concurrent timetables, and amenability to an authentic, collaborative approach. The first subject was an existing third year nursing elective entitled 'Women's Health' which is delivered within a feminist framework in the context of a social model of health. Family violence is a key topic in this subject, and students undertake work-based placements in women's refuges. In this subject students have the opportunity to explore issues related to women's and have the opportunity to test the theoretical claims of the subject in various clinical and women's health service environments.

Secondly, a pilot Architecture elective subject -'Special Project (Design): Seeking Refuge' - was developed as an eight-week elective subject for post-graduate students. This research-based subject required them to analyse the idea of refuge spaces and client narratives which included investigative exercises, architectural precedents and meetings with stakeholders. Students were required to develop particular scenarios and provide spatial responses to the physical and emotional needs of women and children within the refuge. Finally, a subset of the students enrolled in a core third-year landscape subject titled "Landscape Architecture Studio 6: The City participated in the refuge project. This subject enables students to understand and adapt landscape architecture design methodologies through bold, innovative and exploratory projects that address contemporary environmental, ecological and societal challenges. 
The architecture and landscape architecture students formed teams for eight weeks, researching landscape-focused architectural solutions and exploring the relationship between the built and natural spaces. Following this, they worked collaboratively on two assessment tasks: a poster outlining spatial scenarios (hypothetical refuge situations) and a design guide which illustrated 10-12 criteria for design excellence for refuge spaces.

Participating students were briefed on the project requirements and the expected outcomes in class, and were then divided into small groups comprising two nursing and between three and four architecture/landscape students. Collaboration protocols were established at the initial meeting.

All students were addressed by a number of experts from both the refuge sector and the local government sector and had an opportunity to ask questions. By sharing knowledge, ideas and experiences, and through direct contact with stakeholders, new overarching frameworks were created. Site visits to a refuge enabled some of the students to engage with stakeholders and better understand their issues and needs.

Nursing students were required to identify the key health and shelter issues for women and children affected by homelessness and/or family violence. They then provided architecture and landscape students with insights from their research, and architecture and landscape students, in turn, presented their ideas for building and landscape designs and outlined constraints based on their discipline knowledge.

Nursing students were assessed on their ability to research and provide social and health related scenarios of the women and children who sought refuge services and share this information in collaboration with the architecture and design students. They were also asked to reflect on the situation of the service users within a social model of health in a feminist context and compare this to the predominant biomedical model.

\section{Methodology}

\subsection{Aim}

The aim of this project was to explore the potential for authentic, interdisciplinary, collaborative learning to enhance educational and social outcomes for health, architecture and landscape architecture students.

\subsection{Setting or Context}

The research was conducted within the faculty of nursing and school of architecture at one leading metropolitan Australian university during mid semester 2017.

\subsection{Ethical Considerations and Recruitment}

Following ethics approval, students were invited to participate in three focus groups exploring the Refuge Project learning activity. An email was sent to the 46 students enrolled in the three selected courses and reminders were issued in class. Participation was voluntary.

\subsection{Data Collection}

Focus groups were conducted at the conclusion of the activity to ascertain how (or if at all) collaboration in the interdisciplinary context assisted students to develop an understanding of needs of women and children requiring refuge as a result of homelessness or family violence, and to act as agents of social change. The focus group method of obtaining data is one of the most frequently used in healthcare research. Its use in healthcare education, in particular medical education, has increased significantly in the 21st century (Stalmeijer, McNaughton, \& VanMook, 2014). Focus groups are often the principal means of collecting data for program and project evaluation (Stalmeijer, Wolfhagen, \& Scherpbier, 2009; Stergiopoulos, Maggi, \& Sockalingam, 2010). In this case we used focus groups to gauge a) the students' perceptions of the value of the collaborative interdisciplinary learning activity and b) how the activity impacted their feelings about the users of refuge services, and c) the potential for the students to act as agents of social change as a result. The questions asked during the focus groups were:

1. How has working collaboratively helped in your understanding of women who require refuge services?

2. In what way, if any, did your perspective on women who require refuge services change as a result of this collaboration?

3. What was the best aspect of working collaboratively for your learning?

4. What could be done in the future to improve your learning in this collaboration?

5. What could be done in the future to improve the opportunity for you to actively contribute to this community of vulnerable women? 


\subsection{Data Analysis}

A modified version of Hsieh and Shannon's (2005) strategy of summative qualitative content analysis was used for data analysis. Transcripts from the focus group were analysed using a detailed qualitative interpretation to discover the underlying themes and meaning of the words and content. Data analysis began with reading all data repeatedly to achieve immersion and obtain a sense of the whole. Then, data were read word by word to derive themes by first highlighting the exact words from the text that appeared to capture key thoughts or concepts. In addition, careful examination of the data included the context in which key words appeared in order to avoid misunderstanding.

For the content analysis, the participants' responses were de-identified and allocated a number between 1 and 39 . The responses of the nursing and architecture students were separated as the authors wished to identify differences between discipline groups. Participants 1-15 were nursing students, $16-26$ were architecture students and $27-39$ were landscape architecture students. In the following discussion, participant responses are categorized by number. For example, participant 5 is referred to as P5, and so on.

\section{Results}

Thirty-nine students agreed to participate in the focus groups comprising fifteen from nursing, eleven from architecture and thirteen from landscape. This represented a response rate of $84.8 \%$. In terms of demographic differences between the groups, while the students were similarly aged (with an average age of 24 years old, ranging from 19-37), there was a marked variation in the gender distribution: all 15 nursing students were female, eight of the 11 architecture students were female, but only six of 13 landscape students were female. In terms of ethnicity, the nursing students were evenly distributed between three categories - South Asian, East Asian and Caucasian with just one student from the Middle East. Eight of the eleven architecture students were Caucasian, two East Asian and one South Asian, with none in the Middle Eastern category. There was a narrow distribution in the Landscape group, with just two categories represented: eight Caucasian students and five East Asian.

Five main themes emerged from the focus group data: students favor authentic, 'real-life' projects; learning is about feelings and attitudes as well as knowledge; interdisciplinary learning prepares students for the real world of work; collaboration offers valuable new perspectives, ideas and knowledge; and organization is key.

\subsection{Students favor Authentic, 'Real-life' Projects}

Students spoke positively about the learning activity, describing it as an authentic and 'real-life' "meaningful project" (P26). The students recognized that this learning experience was practical, and they were motivated by the potential application of their ideas for real social benefit. One commented that it was "good to know that our ideas are being used" (P16); another said the experience had 'made us all ...thankful for being able to contribute in our way to the refuge centre" (P39).

The authenticity of the experience also provided a reality check for the architecture and landscape students who appreciated that learning was as much about what doesn't work as what does work:

I realised that certain ideas we had wouldn't work in the real world. We realised this after several visits to women's refuges, where our questions and suggestions were answered (P36)

Several architecture and landscape students expressed a desire to continue their design work and see their ideas actually implemented. They wanted "opportunities to design an actual site" (P28), "input into a real project" (P30), "working with something physical" (P22), "to present our design guides to people of significance within this area of women's refuge" (P37), and "to work with an existing refuge to make improvements so, in a way, giving it context, to do more specifically about tangible issues" (P19).

These findings reflect the findings from previous studies about the importance of connecting students' interests with the learning task, ensuring that the activity targets an audience outside the classroom, and that the new knowledge created is valued by others working in the field (Lombardi, 2007; Maina, 2004; Renzulli, Gentry, \& Reis, 2004).

\subsection{Learning is about Feelings and Attitudes as well as Knowledge}

The majority of responses referred to the knowledge gained from the Refuge Project. One spoke of moving from a "superficial" to a "deeper understanding" (P19). It follows that the learning experience challenged some previously-held views. Responses included: "[it] reduced the stereotype that women are all young" (P21). Many students expressed surprise that it was not only young women who sought refuge: "I was surprised by the advanced age of some of the women" (P16). Similarly, students said that they learnt: "there is a greater diversity of women that [sic] access services" (P1), "they can be from different cultural backgrounds" (P2). As well as the "diversity" of the women (P3, P17), the complexity of their needs was noted, as in the observation: "clients in refuges are not just DV 
survivors, they are varied and require more complex solutions than just a bed and kitchen" (P22). "Information-sharing about their personal experiences in the past... has given us in-depth knowledge about their struggles, wants and needs in the shelter space" (P23)

Importantly, a change in the nature and intensity of students' feelings was also evident: some responses suggested a strong new personal response and sense of connection with women accessing refuges based on "understanding their situation" (P27). One student commented "It helps to understand what they have been through" (P3), another spoke of "gain [ing] insight on how the women think" (P9).

There was a sense that some participants were inspired by the women they met. One spoke of having "much more admiration and respect [for] women who went through tragic violencelabuse' (P23), one referred to their "sympathetic" perspective (P29), another said "I feel more sympathetic" (P34), and another spoke of 'empathy' (P12).

Some responses indicated that students were able to extrapolate from the individual client stories a larger social picture, for example, "the degree of vulnerability of women" (P26). Similarly, speaking of family violence and its impact, one student observed that the learning activity, "humanises it [family violence] and brings it back home that this is real and a problem in Australia" (P25).

This reflects the literature which indicates that authentic learning, which brings students into close contact with stakeholders and clients, is more likely than theory-based learning to lead to changed feelings and attitudes. Renzulli et al (2004), for example, note that authentic learning involves an emotional commitment on the part of students, as well as cognitive interest. This commitment, it seems, can extend beyond the life of the learning activity. In our project several students expressed an intention to continue engagement with the sector, for example, through "volunteering" ( $\mathrm{P} 2, \mathrm{P} 15, \mathrm{P} 16, \mathrm{P} 23)$, fund-raising (P23, $\mathrm{P} 25)$ and practical design work: "to work with an existing refuge to make improvements" (P19). Another simply said, "I would like to help them" (P7).

There was also interest in continuing their learning by attending seminars and workshops (P4, P5, P9, P32) which supports the claim that authentic learning can support life-long learning (Barkley 2005).

\subsection{Interdisciplinary Learning Prepares Students for the Real World of Work.}

Students recognized that what they were engaged in as part of an interdisciplinary group of learners was different from the usual discipline-specific experience:

The tension that is created when two disciplines come together is kind of interesting because during studies we generally tend to study in isolation whereas in the field reality is different (P32)

Furthermore, participants saw that the learning activity presented an opportunity to develop relevant skills and knowledge for the world of work after graduation, where "working as a team" (P10) and "challenging ourselves to manage each other/push each other's understanding" (P30), would be important. The new learning was also seen as transferrable to their specific careers, for example a nursing student said it would "help me to learn how to work collaboratively with the patient" (P12), while a landscape architecture student valued "being able to approach design issues with a new lens" (P29).

These views are consistent with the previous research which suggests that while traditional learning is often narrow and exclusive of other perspectives and constrained to 'discipline-specific silos' (Gilligan et al 2014, p2), interdisciplinary learning offers a broader, more holistic experience that generates deeper understandings and a shared conceptual framework (Park \& Son 2010).

\subsection{Collaboration Offers Valuable New Perspectives, Ideas and Knowledge}

Participants' responses indicated how much they valued sharing ideas and knowledge with people with different expertise, working with each other's strengths, and developing new perspectives and linkages. Students spoke positively about gaining an understanding of the scale, range and complexity of family violence and homelessness issues through the new ideas and approaches presented by students from other disciplines. Many also commented that in the process they learnt how to work collaboratively.

A minority of responses were not positive about collaboration. Of the Landscape students, one said, "The collaborative work didn't really help" (P18), another responded "Not much" (P26) and another said "not sure" (P32). One Architecture student was of the view that "Collaboration with health students did not help so much" (P21).

Collaboration was generally described as a way of challenging learners to be open to different ideas and opinions, and to take a broader, more holistic approach: 
Working with students from other courses helps look at the issues from a different perspective, which sometimes leads to new discoveries and information/strategy out of the usual way of responding (P19)

The responses from the Architecture and Landscape students in particular suggested a significant shift in thinking:

It helps to have perspectives from other disciplines, sometimes it's easy to get caught in the basic amenities of refuges - working with landscape students reminds me to think architecturally and spatially. The health students reminded [me] of simple interventions that really help (P22)

It opened up ideas and thoughts that can be seen in another way than the standard architectural thinking (P24)

[It] allowed me to focus on a wide range of needs and not just respond through architecture but view the issue as a whole (P29)

When designing a women's refuge, thinking more [about] what the women think instead of just making] the design 'beautiful' (P38)

\subsection{Organization is Key}

Participants commented on the organisation of the learning activity in regards to the need for clearer roles and planning, more effective scheduling of activities, more structured meetings and more feedback. But the most common observation was that more time was needed for the activity. Nursing students said they wanted 'more time with architecture students' (P11), and more time for 'conversation and discussion' (P7). The architecture and landscape students also wanted additional (or otherwise improved) contact with the nursing students. Nine participants mentioned this with comments including:

More time with health students - combined classes or we could sit in on one of their lectures (P22)

The collaboration with health students could be improved (P25)

Have health students more involved (P29)

Further input from health students (P30)

Some nursing students spoke of the need for 'consistent information between the disciplines' (P1), 'more information from the other group' (P13) and 'clearer instruction' (P17). Architecture and Landscape students wanted more site visits (P8, P10), and one wanted the visits earlier in the semester (P17). Architecture and landscape students also wanted more site visits (P5, P8, P10, P17), and some who had missed the opportunity to talk to clients identified this as an issue (P16, P23, P32).

Architecture and landscape students expressed a strong desire for more 'hands-on' work" (P6), for example, a 'full design project' (P21), 'a location/site to be working on would be great to narrow down all of our brainstormed ideas' (P23), 'site-specific design responses' (P37), 'a site, rather than floating ideas into space' (P35). Some also expressed a wish for 'one assessment project' (P24) and 'integrated tasks between architecture and health' (P18).

While these comments can be seen as criticisms, in fact they reflect the success of the activity in engaging and motivating students, and can certainly be of benefit in the future refinement of the learning activity, especially in regard to the importance of group formation and support (Cawkwell, Talbot, \& Boylan, 2016).

\section{Discussion}

The findings indicate that authentic, interdisciplinary, collaborative learning opportunities can be an effective means of enhancing students' learning and assisting them to develop the requisite skills and disposition to act as agents of social change. Because the architecture and landscape students were required to formulate design principles for their assessment task, the project offered an outcome of practical value to those working in the field, giving the learning activity more meaning and relevance. As well as learning in the classroom and attending small-group meetings with peers from the other two disciplines, students conducted self-directed research and visited sites. They heard from refuge workers and board members as well as staff from the local council who provided an insight into the local community. The intersection between lived experience and disciplinary knowledge provided a meaningful context for authentic learning to occur (Tochon, 1996). The learning was also scaffolded, providing support for learners to address new challenges and apply new knowledge and skills to real-world scenarios (Quarles, Lampotang, Fischer, Fishwick, \& Lok, 2009).

The learning activity met the four criteria for authentic learning identified by Renzulli et al. (2004): the problem students investigated was 'real-life' and involved an emotional and a cognitive element, no 'set answers' were 
available, the solutions students devised had the potential to effect real change, and their work was for real people outside the classroom. The learning activity also provided opportunities for students to develop 'portable' skills for their future professional roles, another key element of authentic learning according to Herrington et al. (2014) and (Lombardi, 2007). The latter identifies these skills as 'distinguishing reliable from unreliable information (judgment), following longer arguments across multiple modalities (synthesis), discovering and sharing relevant information in a credible manner (research), learning an abstract concept by applying it appropriately in real-world contexts (practice), and generating alternative solutions that work across disciplinary and cultural boundaries (negotiation)'.

Recognised benefits accrue when teaching and learning initiatives transcend traditional disciplinary boundaries: unexpected linkages can be found and surprising new knowledge and knowledge frameworks can emerge. Participating students identified two main benefits of working collaboratively with students and stakeholders from other disciplines: subject knowledge and process knowledge. That is, students reported that they not only learnt more about family violence and homelessness than they would have working within a single discipline framework, but they also learnt how to collaborate with others, which they recognized that this was a useful, transferrable skill.

Collaboration allows learners to build knowledge, challenge assumptions (their own and those of others) and uncover opportunities. As Bucciarelli (2002) argues, in design it can be as much about developing a shared understanding as it is a matter of generating concepts, costing and sizing. The aim of working collaboratively may, in fact, be to gain insight and to learn, rather than to produce a solution to a specific problem (Feast, 2012).

Collaboration with others assists both creativity and problem-solving, core components of innovation. Creative activity has been said to grow out of the relationship between individuals and their work, and from the interactions between an individual and other human beings (Fischer, 2005, p. 28). The learning activity used the technique of scenario building to prompt knowledge-sharing, testing of ideas, negotiation and problem-solving. This saw the student-as-architect present a scenario of building use to the nursing student-as-client, which opened up richer and more diverse design conversations (McDonnell, 2009). Learning beyond the boundaries of a single subject discipline can transform learners and effect real-world change.

\section{Conclusion}

This novel educational project allowed learners entree into the lived experience of women and children affected by family violence and homelessness through direct engagement with refuge clients and stakeholders. It caused them to examine their preconceptions, to reflect on the lived experiences of this vulnerable group, and to respond both personally and professionally to their feelings, perspectives, needs and concerns. The interdisciplinary interactions challenged students' thinking and opened up diverse new approaches and the emergent understandings assisted students to translate their learning into a series of proposals for a women's refuge. The results of the study attest to the impact of authentic, interdisciplinary, collaborative learning to both enhance knowledge acquisition and help students develop the skills, confidence and disposition to be agents of social change.

A follow up study to explore the potential of authentic, interdisciplinary learning to enhance knowledge acquisition, work-readiness, empathy and social agency based on this pilot project would make a valuable contribution to the literature. A particularly interesting study would be a follow-up study to ascertain if the expressed commitment of the participants to supporting the refuge sector continues after graduation. That is, has the learning had a lasting impact on students in regard to their social agency?

\section{Acknowledgments}

The authors would like to acknowledge the support of the following: UTS Social Research Grant awarded to support the project; Board Director and staff at Hornsby Ku-ring-gai Women's Shelter; Mayor of Ku-ring-gai Council; UTS Centre for Social Justice and Inclusion; Faculty for Transdisciplinary Innovation.

\section{References}

AIHW. (2007). Demand for SAAP accommodation by homeless people 2005-06: a report from the SAAP national data collection. Australian Institute of Health and Welfare.

AIHW. (2016). Domestic \& family violence and homelessness 2011-12 to 2013-14. Retrieved from Canberra, ACT:

Aitamurto, T. (2015). Crowdsourcing as a knowledge search method in digital journalism: ruptured ideals and blended responsibility. Journal of Digital Journalism, 4(2), 280-297. https://doi.org/10.1080/21670811.2015.1034807 
Baker, C., Cook, S., \& Norris, F. (2003). Domestic violence and housing problems: a contextual analysis of women's help-seeking, received informal support, and formal system response. Violence Against Women, 9(7), 754-783. https://doi.org/10.1177/1077801203009007002

Barkley, E., Cross, K., \& Major, C. (2005). Collaborative learning techniques: a handbook for college faculty. San Francisco, USA: Wiley.

Bateman, R., \& Craig, C. (2015). Developing interdisciplinary learning and teaching approaches to promote socially responsible design practices In a Planet of Our Own. Mumbai.

Boix Mansilla, V., \& Gardner, H. (2000). On disciplinary lenses and interdisciplinary work. In S. Wineburg \& P. Grossman (Eds.), Interdisciplinary curriculum challenges of implementation. New York, NY: TC Press.

Bonney, R., Shirk, J., Phillips, T., Wiggins, A., Ballard, H., Miller-Rushing, A., \& Parris, K. (2014). Next steps for citizen sicence. Science, 343(6178), 1426-1437. https://doi.org/10.1126/science.1251554

Bryson, C. (2016). Engagement through partnership: students as partners in learning and teaching in higher education. International Journal for Academic Development, 21(1), 84-86. https://doi.org/10.1080/1360144X.2016.1124966

Bucciarelli, L. (2002). Between thought and object in engineering design. Design Studies, 23(3), 219-231. https://doi.org/10.1016/S0142-694X(01)00035-7

Cawkwell, J., Talbot, A., \& Boylan, M. (2016). Beginning collaborative learning: student and staff perspectives on its value and challenges. Student Engagement and Experience Journal, 5(1).

Feast, L. (2012). Professional perspectives on collaborative design work. Co-design, 8(4), 225. https://doi.org/10.1080/15710882.2012.734828

Fischer, G. (2005). Distances and diversity: sources for social creativity. Paper presented at the The 5th ACM Conference on Creativity and Cognition, London, UK. https://doi.org/10.1145/1056224.1056243

Gibbs, P. (2017). Should contentment be a key aim in higher education? Educational Philosophy and Theory, 49(3), 242-252. https://doi.org/10.1080/00131857.2016.1214898

Gilligan, C., Outram, S., \& Levett-Jones, T. (2014). Recommendations from recent graduates in medicine, nursing and pharmacy on improving interprofessional education in university programs: a qualitative study. $B M C$ Medical Education, 1452. https://doi.org/10.1186/1472-6920-14-52

Goldsmith, E. (2016). Domestic and family violence and homelessness in New South Wales. Parity, 29(10), 31-32.

Herrington, J., Reeves, T., \& Oliver, R. (2014). Authentic learning environments. In J. Spector, M. Merrill, J. Elen, \& M. Bishop (Eds.), Handbook of Research on Educational Communications and Technology. New York, NY: Springer. https://doi.org/10.1007/978-1-4614-3185-5_32

Hsieh, H., \& Shannon, S. (2005). Three approaches to qualitative content analysis. Qualitative Health Research, 15(9), 1277-1288. https://doi.org/10.1177/1049732305276687

Iwasiw, C., Goldenberg, D., \& Andrusyszyn, M. (2014). Curriculum Development in Nursing Education. Mass. US: Jones and Bartlett.

Knotts, G., Henderson, L., Davidson, R., \& Swain, J. (2009). The search for authentic practice across the disciplinary divide. College Teaching, 57(4), 188-196. https://doi.org/10.1080/87567550903218562

Kreber, C. (2016). Educating for civic-mindedness: nurturing authentic profesional identities through transformative higher education. London, UK: Routledge.

Lombardi, M. (2007). Approaches that work: how authentic learning is transforming higher education. Retrieved from Bounder, CO:

Maina, F. (2004). Authentic learning: perspetives from contemporary educators. Journal of Authentic Learning, 1-8.

Mansilla, V. B., \& Duraising, E. D. (2007). Targeting assessment of students' interdisciplinary work: an empirically grounded framework proposed. Journal of Higher Education, 78(2), 215-237. https://doi.org/10.1080/00221546.2007.11780874

McDonnell, J. (2009). Collaborative negotiation in design: a study of design conversations beween architect and building users. CoDesign, 5(1), 44. https://doi.org/10.1080/15710880802492862 
Moore, R. (2016). Women, family violence and homelessness: trauma informed care as a standard, not a specialty. Parity. Retrieved from http://search.informit.com.au.ezproxy.lib.uts.edu.au/documentSummary;dn=143323259143671;res=IELFSC>

Park, J., \& Son, J. (2010). Transitioning toward interdisciplinary learning in a multidisciplinary environment. International Journal of Pedagogies and Learning, 6(1), 82-93. doi:http://eprints.usq.edu.au/id/eprint/8821

Pohl, C. (2011). What is progress in transdisciplinary research? Futures, 43(6), 618-626. https://doi.org/10.1016/j.futures.2011.03.001

Quarles, J., Lampotang, S., Fischer, I., Fishwick, P., \& Lok, B. (2009). Scaffolded learning with mixed reality. Computers \& Graphics, 33(1), 34-36. https://doi.org/10.1016/j.cag.2008.11.005

Renzulli, J., Gentry, M., \& Reis, S. (2004). A time and a place for authentic learning. Educational Leadership, 62(1), 73-77.

Rule, A. (2006). The components of authentic learning. Journal of Authentic Learning, 3(1), 1-10.

Sonnenwald, D. (1996). Communication roles that support collaboration during the design process. Design Studies, 17(3), 277-301. https://doi.org/10.1016/0142-694X(96)00002-6

Spelt, E. J. H., Luning, P. A., van Boekel, M. A. J. S., \& Mulder, M. (2009). Teaching and learning in interdisciplinary higher education: a systematic review. Educational Psychology Review, 21, 365. https://doi.org/10.1080/03043797.2014.987647

Spelt, E. J. H., Luning, P. A., van Boekel, M. A. J. S., \& Mulder, M. (2015). Constructively aligned teaching and learning in higher education in engineering: what do students perceive as contributing to the learning of interdisciplinary thinking? European Journal of Engineering Education, 40(5), 459-475. https://doi.org/10.1080/03043797.2014.987647

Stalmeijer, R., McNaughton, N., \& VanMook, W. (2014). Using focus groups in medical education research: AMEE Guide No. 91. Medical Teacher, 36(11), 923-939. https://doi.org/10.3109/0142159X.2014.917165

Stalmeijer, R., Wolfhagen, I., \& Scherpbier, A. (2009). Cognitive apprenticeship in clinical practice: Can it stimulate learning in the opinion of students? Advanced Health Science Education, 14(4), 535-546. https://doi.org/10.1007/s10459-008-9136-0

Stergiopoulos, V., Maggi, J., \& Sockalingam, S. (2010). Teaching and learning the physician manager role: psychiatry residents' perspectives. Medical Teacher, 32(7), e308-e314. https://doi.org/10.3109/0142159X.2010.488706

Tochon, F. (1996). The effectiveness of peer tutoring in further and higher education: a typology and review of the literature. Higher Education, 32(3), 321-345. https://doi.org/10.1007/BF00138870

UTS. (2017). University of Technology Sydney Retrieved from https://www.uts.edu.au/

Wall, S., \& Shankar, I. (2008). Adventures in transdisciplinary learning. Studies in Higher Education, 33(5), 551-565. https://doi.org/10.1080/03075070802373008

Zou, C. (2016). The shape of higher education. Paper presented at the The 39th International Conference of the Higher Education Research and Development Society of Australasia (HERDSA), Fremantle, Western Australia. 